\title{
Erratum zu: Anhang
}

\section{Erratum zu:}

\section{Kapitel 10 in: T. Carolus, Ventilatoren https://doi.org/10.1007/978-3-658-29258-4_10}

Die Originalversion des Buchs wurde revidiert. Aufgrund eines Versehens wurden in den Tabellen 10.5 und 10.6 im Anhang auf den Seiten 204 und 205 falsche Zahlenangaben im Index wiedergegeben. Wir bitten den Fehler zu entschuldigen. Die Tabellen wurden korrigiert.

Die korrigierte Version des Kapitels ist verfügbar unter https://doi.org/10.1007/978-3-658-29258-4_10 